\title{
Some determinants of response summation
}

\author{
AYDAN AYDIN and JOHN M. PEARCE \\ University of Wales Cardiff, Cardiff, Wales
}

\begin{abstract}
Response summation in pigeons was examined in four experiments. In Experiment 1, summation was not found with a compound of two visual stimuli on a television screen after they had individually been used for instrumental conditioning. In this experiment, the training and test trials were separated by an interval during which the television screen was dark. Summation was found in Experiment 2 for which the television screen was permanently white during the interval between trials and in the region that was not occupied by the experimental stimuli. These results were replicated using a within-subject design (Experiment 3) and autoshaping (Experiment 4). Experiment 2 also revealed summation with compounds of auditory and visual stimuli, but not with compounds of two auditory stimuli or two diffuse lights. The results can be explained by a variety of theories of learning, if they take account of generalization between the stimuli.
\end{abstract}

When two or more stimuli that have individually been paired with the same reinforcer are presented together, performance during the compound can be stronger than during its components. This summation effect has been demonstrated with a variety of tasks. Examples of successful summation with Pavlovian conditioning have been obtained using eyelid conditioning with rabbits (Kehoe, 1986; Whitlow \& Wagner, 1972), conditioned suppression with rats (Hendry, 1982; Wagner, 1971), and salivary conditioning with dogs (Konorski, 1948, pp. 109-114). Using appetitive operant conditioning, summation has been found with rats (Hamm, Porter, \& Oster, 1978; Strub \& Barske, 1977; Weiss, 1977) and pigeons (Long \& Allen, 1974; Meltzer \& Hamm, 1976). Summation has also been reported with avoidance responding using dogs (LoLordo \& Hart, 1972) and rats (Emurian \& Weiss, 1972; Van Houten \& Rudolph, 1971; Weiss, 1976, 1977).

The many different ways in which summation has been demonstrated suggest that this effect will be found with any species that is susceptible to conditioning and with any conditioning procedure. There are, however, grounds for questioning this conclusion. In the case of pigeons, for example, summation appears to be found in some circumstances but not others. Thus, using autoshaping, there are at least three reported failures to obtain summation (Aydin \& Pearce, 1994, 1995; Rescorla \& Coldwell, 1995). As far as operant conditioning with pigeons is concerned, there are several successful demonstrations of summation (Long \& Allen, 1974; Meltzer \& Hamm, 1976; Millier \& Beale, 1977; Wiltz, Boren, Moerschbaecher, Creed, \& Schrot, 1973), but these are matched by an equal number of reported failures to obtain this effect (Hamm, 1977; Hamm \& Meltzer, 1973; Meltzer \& Hamm, 1976; Millier $\&$ Beale, 1977).

This research was supported by a research grant from the UK BBSRC and by a studentship from the Turkish government. Correspondence should be addressed to A. Aydin or J. M. Pearce, School of Psychology, University of Wales Cardiff, Cardiff CF1 3YG, Great Britain.
The purpose of the present paper is to examine in some detail the factors that determine whether or not summation will be observed with pigeons. At an empirical level, the experiments might reveal if there is something distinctive about this species when summation tests are conducted. The experiments may also enhance our understanding of the mechanisms of summation by providing further information about the circumstances in which this effect can be seen.

\section{EXPERIMENT 1}

A common feature of a number of experiments that have failed to reveal summation with pigeons is the use of Pavlovian conditioning (Aydin \& Pearce, 1994; Rescorla \& Coldwell, 1995). In contrast, experiments using operant conditioning have been more successful in demonstrating summation with this species. The possibility is thus raised that for pigeons summation is more likely to be found after conditioning with an operant schedule rather than a Pavlovian schedule. In order to evaluate this possibility, the design of Experiment 1 was based on an experiment by Aydin and Pearce (1995, Experiment 1), which failed to find summation using autoshaping. In that experiment, food was presented after two colored triangles (A and B), but not after two other colored triangles $(C$ and $D)$. Test trials then revealed that responding during $\mathrm{AB}$ was no faster than during either $\mathrm{A}$ or $\mathrm{B}$ alone. One implication of this finding is that it is not possible to obtain summation with autoshaping. As a step toward evaluating this possibility, the present experiment used the same stimuli as those in the study by Aydin and Pearce (1995), but food was delivered according to an instrumental schedule rather than a Pavlovian schedule in the presence of $A$ and $B$. Pecks in the presence of $C$ and $D$ were never followed by food. Once a consistently high rate of responding had been established to $A$ and $B$, compound $\mathrm{AB}$ was presented for testing. Evidence of faster responding during $A B$ than either $A$ or $B$ would then 
strongly suggest that it was indeed the use of a Pavlovian reinforcement schedule that was responsible for our previous failure to find summation. In fact, responding during $\mathrm{AB}$ was no faster than during either $\mathrm{A}$ or $\mathrm{B}$. This absence of summation may have occurred because responding was already at a maximum rate when $A B$ was introduced. Accordingly, the original discrimination was reversed for the remaining training sessions, which were then followed by test trials with C, D, and CD in extinction. In passing, we can note that Long and Allen (1974) found summation when pigeons were tested during extinction, but not during conditioning.

A further finding from studies with pigeons using operant conditioning is that the outcome of a summation test is influenced by the reinforcement schedule. When food is made available according to a variable-interval (VI) schedule with a mean interval of 1 min or less, then summation may not be seen (Hamm, 1977; Hamm \& Meltzer, 1973; Long \& Allen, 1974; Meltzer \& Hamm, 1976); however, it is more likely to occur with longer intervals (Meltzer \& Hamm, 1976; Millier \& Beale, 1977). For Experiment 1, therefore, subjects were trained with a VI reinforcement schedule, with the mean value for the interval being extended gradually to $2 \mathrm{~min}$.

\section{Method}

Subjects. The subjects were 18 adult pigeons that had participated in a previous autoshaping experiment with vertical colored rectangles $(5.5 \times 1.4 \mathrm{~cm}$ ) as stimuli (see Aydin \& Pearce, 1994, for details). The pigeons were housed in pairs and had free access to water and grit in their home cages. They were maintained at $80 \%$ of their free-feeding weights by being fed a restricted amount of food after each experimental session. The pigeons were maintained in a lightproof room in which the lights were on for $14.5 \mathrm{~h}$ each day.

Apparatus. The experimental apparatus consisted of eight pigeon test chambers $(30 \times 33 \times 35 \mathrm{~cm})$. Each contained a three-key pigeon panel (Campden Instruments Ltd., Loughborough, England), the center key of which was replaced by a $4.5 \times 5.0 \mathrm{~cm}$ clear Perspex panel that was hinged at the top. Pecks on the panel were detected by a reed relay that was operated whenever a magnet attached to its lower edge was displaced by a distance greater than $1 \mathrm{~mm}$. The midpoint of the panel was $24 \mathrm{~cm}$ above the floor of the chamber. A Panasonic microcolor television with a $5.5 \times 4.4 \mathrm{~cm}$ screen was located $4.0 \mathrm{~cm}$ behind the Perspex panel. Food was delivered by operating a grain feeder (Campden Instruments Ltd.), which was located below the Perspex panel. The feeder was illuminated whenever grain was made available. The chambers were permanently lit during all experimental sessions by a $2.8-\mathrm{W}$ bulb, operated at $24 \mathrm{~V}$, located $2.5 \mathrm{~cm}$ above the top of the Perspex panel. BBC microcomputers (Acorn Computers Ltd., Cambridge, England), which were programmed in SPIDER (Paul Fray Ltd., Cambridge, England), were used for the control of events, the recording of responses, and the generation of stimuli on the television screens.

Stimuli. The stimuli were colored triangles that occupied the area either below or above a line that joined the top right-hand corner to the bottom left-hand corner of the television screen. Triangles $A$ and $C$ were presented in the upper triangle, whereas $B$ and $D$ occupied the lower triangle. For half of the subjects, A was red, B was green, $\mathrm{C}$ was composed of alternating cyan and blue diagonal lines, each of which was $0.2 \mathrm{~cm}$ wide, and D was white. For the remaining subjects, Triangles $A, B, C$, and $D$, respectively, were the same as Triangles $\mathrm{C}, \mathrm{D}, \mathrm{A}$, and $\mathrm{B}$ that have just been described. When- ever a single triangle appeared by itself, the remainder of the screen was black. For trials with $\mathrm{AB}$ or $\mathrm{CD}$, the two triangles were separated by a black line that was $0.4 \mathrm{~cm}$ wide.

Procedure. In every session of the experiment, apart from the test sessions, there were six 2-min trials with each of A, B, C, and $D$. The stimuli were presented in a random sequence with the constraint that there were no more than two trials of the same type in succession. There was a 20 -sec intertrial interval (ITI) between successive trials during which the television screen was dark. For Stage 1 , the subjects were reinforced for pecking the response panel during $\mathrm{A}$ and $\mathrm{B}$. The timer for the single VI reinforcement schedule started at the onset of these stimuli and stopped at their offset. The values for the schedule were based on the distribution of values described by Fleshler and Hoffman (1962). The first response to occur after a selected interval of the schedule had elapsed resulted in the presentation of food for $4 \mathrm{sec}$ and started the timer for the next interval. A VI 60-sec schedule was used for Sessions 1-10, a VI 90-sec schedule was used for Sessions 11-17, and a VI 120sec schedule was used for the remainder of the experiment.

Testing for Stage 1 was conducted in Sessions 23, 24, 25, and 26. In each test session, there were four trials with each of $A B, A$, and $B$, during which the subjects were reinforced for responding, and six nonreinforced trials with each of $C$ and $D$. The order of presentation was random, with the restriction that the same type of trial did not occur more than once in succession.

For the first 12 sessions of Stage 2, which commenced in Session 27, the subjects were reinforced for responding during $C$ and $\mathrm{D}$, but not $\mathrm{A}$ and $\mathrm{B}$. There were then two extinction test sessions in each of which there were four trials with each of C, D, and CD, and six trials with $A$ and $B$. The trials were in a random sequence, and the same type of trial did not occur more than once in succession. Food was not presented in these two sessions.

\section{Results}

For all the statistical tests, a .05 significance level was used.

From the initial sessions onward in Stage 1, responding was faster during $A$ and $B$ than during $C$ and $D$. The combined mean rates of responding for the four test sessions at the end of this stage during $\mathrm{A}, \mathrm{B}, \mathrm{AB}, \mathrm{C}$, and $\mathrm{D}$, respectively, were $44.8,47.9,48.0,0.9$, and 0.6 responses per minute. A comparison of individual mean rates of responding revealed that every subject responded faster during each of $A, B$, and $A B$ than either $C$ or D. A one-way analysis of variance (ANOVA) using the individual mean rates of responding from the four sessions during $\mathrm{A}, \mathrm{B}$, and $\mathrm{AB}$ revealed a nonsignificant effect of stimulus $[F(2,34)=$ $2.0]$. Thus, the analysis confirms that the differences between responding during $\mathrm{AB}$ and its components were not significant.

In case any summation effect with $\mathrm{AB}$ was transient, the results for only the first test session were also examined. It was not possible to analyze the results from the first trials of this session, because they were not recorded separately. In this session, the mean rates of responding during $A, B$, and $A B$, respectively, were $41.2,48.4$, and 51.7 responses per minute. A one-way ANOVA revealed that this difference was significant $[F(2,34)=8.1]$. NewmanKeuls comparisons then indicated that responding during $A$ was slower than during either $B$ or $A B$, but the difference between the response rates during $A B$ and $B$ was not significant. In view of this last finding, we must conclude 
that, even on the first test session, there was no convincing evidence of summation.

In Stage 2, the reversal of the training used in Stage 1 was successful: The rate of responding during $A$ and $B$ declined gradually and, for most subjects, the rate of responding increased during $C$ and $D$. The results from 4 subjects that failed to peck during $C$ and $D$ have not been included in the following analysis. The mean rates of responding per minute by the final session of instrumental conditioning, Session 38, during A, B, C, and D, respectively, were $8.1,9.5,43.4$, and 45.8 . A comparison of the individual mean rates of responding for this session revealed that each of the 14 subjects responded more rapidly during $C$ and $D$ than during either $A$ or $B$.

Figure 1 shows the mean rates of responding during $C$, $\mathrm{D}$, and $\mathrm{CD}$ for the extinction test trials. The graph, overall, suggests that the rate of responding during $C D$ was much the same as during either $C$ or D. A two-way ANOVA with the factor of stimulus and trial revealed that the effect of stimulus $[F(2,26)=2.3]$ and the stimulus $\times$ trial interaction $[F(14,182)=1.6]$ were not significant. The effect of trial $[F(7,91)=25.6]$ was significant.

There is a hint in Figure 1 that responding at the outset of testing was more rapid during $C D$ than during the presentation of the two stimuli alone. However, a one-way ANOVA of the results from the first test trial with each of $\mathrm{C}, \mathrm{D}$, and $\mathrm{CD}$ failed to reveal a significant effect $(F<1)$.

\section{Discussion}

Responding in the presence of a compound of two visual stimuli that had separately signaled the availability of food for keypecking was no more rapid than that dur-

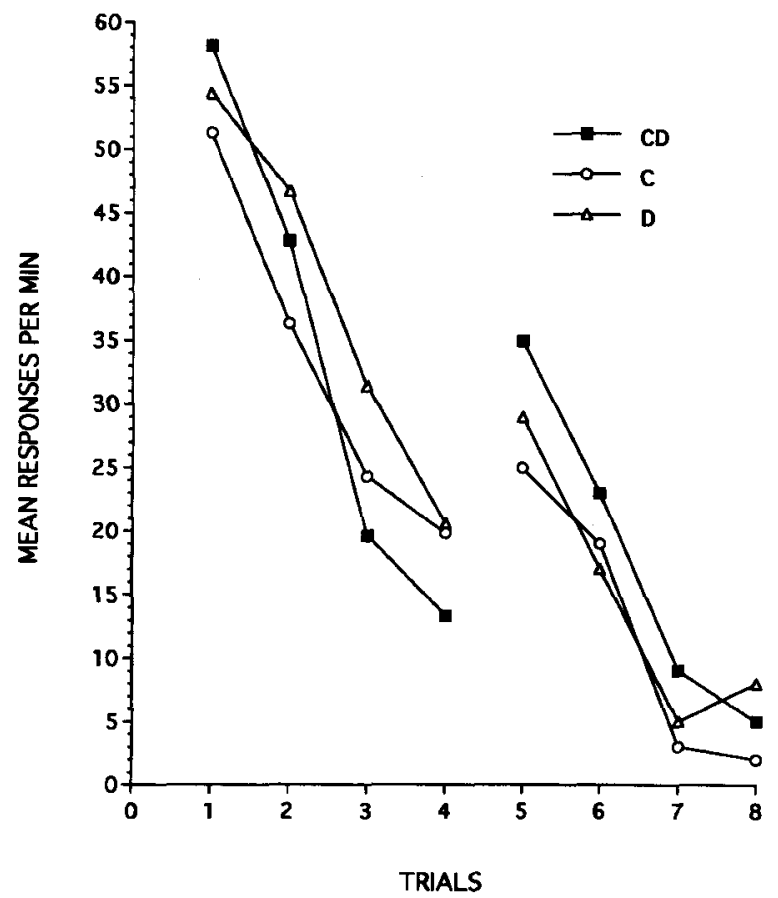

Figure 1. The results from the test trials of Experiment 1 in which $C, D$, and $C D$ were presented in extinction. ing either stimulus alone. This failure to observe summation is entirely consistent with the results of an experiment that used similar stimuli and that failed to reveal summation when the method of conditioning was autoshaping (Aydin \& Pearce, 1995). The possibility remains that, for pigeons, summation is more likely to be found with instrumental conditioning than with Pavlovian conditioning. Alternatively, the factor that prevented a successful demonstration of summation in the above experiment may also have been responsible for the failures to obtain summation with autoshaping. This possibility is examined in more detail in Experiment 4.

The present results conflict with a number of successful demonstrations of summation using operant conditioning with pigeons (Long \& Allen, 1974; Meltzer \& Hamm, 1976; Millier \& Beale, 1977; Wiltz et al., 1973). There is a variety of reasons why our experiment was less successful than these others. First, Hamm (1977) was unable to demonstrate summation with two visual stimuli that were projected together onto a response key. In Wiltz et al.'s (1973) study, summation was obtained with two visual stimuli that were located $3.6 \mathrm{~cm}$ apart and about $3 \mathrm{~cm}$ from the response key. Perhaps, when visual stimuli are used, summation is more likely to occur during the compound when the individual stimuli are presented in different places, rather than together on a response key. In keeping with this suggestion, Rescorla and Coldwell (1995) have proposed that summation in autoshaping is difficult to observe because when two visual stimuli are presented together, they will interact at a perceptual level, and this will diminish their influence on responding. Such a perceptual interaction may be more likely to occur when the stimuli are placed close together than when they are at some distance from each other.

A second explanation is based on the manner in which the response key is illuminated. In many of the successful demonstrations of summation, the response key was permanently illuminated throughout the experimental session. Responding on the key then resulted in food when an additional stimulus was present- - such as a houselight, a tone, or a shape projected onto the illuminated key-but not when these stimuli were absent (Long \& Allen, 1974; Meltzer \& Hamm, 1976; Millier \& Beale, 1977). In our experiment, the television screen behind the response key was dark during the periods when the operant schedule was not in effect. If the television screen had been illuminated during these periods, then the experiment might have been more successful.

A third possibility is raised when the results from summation experiments with species other than pigeons are considered. Using rats (Miller, 1971, 1974) and rabbits (Kehoe, Horne, Horne, \& Macrae, 1994), summation has been shown to be more likely to occur when stimuli from different modalities are combined than when stimuli from the same modality are combined. In a similar vein, there are more reports with pigeons of successful summation using operant conditioning when the test compound is composed of an auditory and a visual element (Long \& Allen, 1974; Meltzer \& Hamm, 1976; Millier \& 
Beale, 1977) than when it is composed of two visual elements (Wiltz et al., 1973). In addition, using autoshaping, Rescorla and Coldwell (1985) found that a compound composed of a diffuse light and a noise that separately signaled food was more effective as a reinforcer for secondorder conditioning than was either of these elements alone. Such an effect was not observed, however, when two visual stimuli were used as reinforcers for second-order conditioning. Taken together, these results imply that summation with pigeons is less likely to be found with compounds composed of stimuli from the same modality than with those composed of stimuli from different modalities.

\section{EXPERIMENT 2}

The purpose of Experiment 2 was to examine in more detail the importance of each of the above three factors for summation. For this experiment, pigeons were first trained to peck at a Perspex panel in front of the television screen in the presence of six individually presented stimuli. The six stimuli were a tone $(T)$, a clicker $(C)$, an illuminated green panel on a side wall $(G)$, an illuminated red panel on a side wall (R), and two triangles (A and $B$ ) similar to those used in Experiment 1. For Group Adjacent, the green panel was placed immediately above the red panel; for Group Separate, these lights were attached to opposite walls of the conditioning chambers. Throughout the experiment, the screen behind the Perspex panel was illuminated white; whenever A or B was presented, the remainder of the screen was also white.

Once conditioning with the six discriminative stimuli was complete, testing took place with the following compounds and their components: AB, AG, AT, GT, GR, and CT. If summation is more likely to occur during a compound of stimuli from different modalities than during a compound of stimuli from the same modality, then AT and GT should elicit faster responding than should any other compound. If the distance between two visual stimuli is an important factor for determining summation, responding during GR should be faster in Group Separate than in Group Adjacent, and summation should be evident with $A G$ but not $A B$. Finally, if the illumination of the response key during the ITI is an important determinant of summation, then responding during all the compounds (including $\mathrm{AB}$ ) will be faster than that during their components.

One interesting outcome from the test trials was that responding was indeed faster during $\mathrm{AB}$ than during either A or B. In order to explore this result further, two additional tests were conducted. The first test comprised presentations of each of $A$ and $B$, during which the remainder of the screen was either black or white. The second test included presentations of $\mathrm{A}, \mathrm{B}, \mathrm{AA}, \mathrm{BB}$, and $\mathrm{AB}$.

\section{Method}

Subjects. The subjects were 30 adult pigeons that had previously participated in autoshaping experiments. They had been trained first with the stimuli referred to in the section describing the subjects for Experiment 1 and then with small colored rectangles $(0.13 \times$ $0.14 \mathrm{~cm}$ ) similar to those described in Pearce and Redhead (1993). The method of housing and the conditions of deprivation were the same as those for Experiment 1. The subjects were randomly allocated in equal numbers to two groups at the start of the experiment.

Apparatus and Stimuli. The eight conditioning chambers of Experiment 1 were used with a number of modifications. First, two 5-ohm loudspeakers were located behind the front wall of the chambers in order to generate a $2-\mathrm{kHz}$ tone at an intensity of $76-\mathrm{dB}$ and an $8-\mathrm{Hz}, 76-\mathrm{dB}$ clicker. Second, two $8 \times 15 \times 4.5 \mathrm{~cm}$ plastic boxes were attached to each of the chambers. The front of these boxes was made of either translucent red or green Perspex. A panel of green or red light $(8 \times 15 \mathrm{~cm})$ could then be generated by operating at $24 \mathrm{~V}$ three 2.8 -W bulbs that were inside the boxes. These light sources were sufficiently bright to allow the appropriate color to be reflected from each of the aluminum walls and the ceiling of the conditioning chambers. The green light source was attached to the right-hand wall beside the top corner of the front panel. For Group Adjacent, the red light source was attached immediately beneath the green light source. For Group Separate, the red light source was on the left-hand wall directly opposite the green light source. Stimuli A and B were triangles of the same dimensions as their namesakes in Experiment 1. Triangle A was composed of alternating blue and cyan diagonal stripes and was presented in the upper part of the television screen. Triangle B was magenta and was presented in the lower part of the screen. Whenever A or B was presented, the remaining half of the screen was white, unless stated otherwise. Whenever two triangles were presented simultaneously, they were separated by a white diagonal line, which was $0.4 \mathrm{~cm}$ wide. In the absence of $A$ and $B$, the entire television screen was illuntinated white.

Procedure. In every session of the experiment, there were three 2-min presentations with each of $A, B, T, C, G$, and $R$ in a random order, with the restriction that each trial was different from its predecessor. The interval between successive trials was $2 \mathrm{~min}$, during which the television screen was illuminated white. Six VI 60-sec reinforcement schedules were separately in effect during the six discriminative stimuli for Sessions 1-10, thereafter the reinforcement schedules were VI $120 \mathrm{sec}$.

Tests with $C T, A G, A T, G R, A B$, and $G T$. Testing for summation with the six compounds was conducted in Sessions 16, 17, and 18. The test procedure was then repeated in Sessions 20, 21, and 22. Each test session contained the same trials as those in the training stage, plus an additional two trials with the following pairs of compounds: $C T$ and $A G, A T$ and GR, or $A B$ and GT. The sequence with which these pairs were presented varied for different subgroups of 5 subjects in each group. Food was never presented during the compounds. The test sessions also included one test trial with each of the components of the test compounds. For these tests, in which food was not presented, a training trial with the appropriate stimulus was selected at random. The sequence of test trials was random with at least one training trial between successive test trials.

Tests with $A$ and $B$. In each of Sessions 24 and 25 , there was a single test trial with $A$ and with $B$ while the remainder of the screen was black. One of the three training trials with $A$ and with $B$, when the remainder of the screen was white, was also treated as a test trial. The four test trials in each session were conducted in extinction, and there were at least three training trials between successive test trials.

Tests with $A A$ and $B B$. During both Sessions 30 and 31 , there was a single presentation of $\mathrm{AA}$ and of $\mathrm{BB}$ with the same stimulus, $\mathrm{A}$ or $B$, presented on both halves of the screen separated by a $0.4-\mathrm{cm}$-wide white diagonal line. There was a single presentation of $A B$ in each of these sessions. In addition, one of the three training trials with $A$ and with $B$ was treated as a test trial. Again, the test trials were conducted in extinction and were presented in a random order. There were at least two training trials between successive test trials. Procedural details that have been omitted were the same as those for Experiment 1 


\section{Results}

From the initial sessions onward, responding was faster during the discriminative stimuli than during the ITI. The combined mean rates of responding for the test sessions with the compounds during each of the six discriminative stimuli and the ITI are presented in Figure 2. A comparison of the individual rates of responding showed that every subject responded more rapidly during each type of test trial than during the ITI. Figure 2 shows that responding was faster during the stimuli presented on the screen (A and B) than during the green and red lights ( $G$ and $R$ ) and that responding during these lights was, in turn, faster than that during the two auditory stimuli $(\mathrm{C}$ and $\mathrm{T}$ ). A one-way ANOVA, using individual combined rates of responding during $A$ and $B, G$ and $R$, and $C$ and $\mathrm{T}$, revealed a significant effect of stimulus $[F(2,58)=$ 11.6]. Subsequent Newman-Keuls comparisons confirmed that responding was significantly faster during $A$ and $B$ than during either $G$ and $R$ or $C$ and $T$. Responding was also significantly faster during $G$ and $R$ than that during $\mathrm{C}$ and $\mathrm{T}$.

Tests with CT, AG, AT, GR, AB, and GT. Figure 3 presents the combined mean rates of responding for the two test presentations with each type of compound and its components. Figure $3 \mathrm{~A}$ shows that the rate of responding during $\mathrm{AB}$ was higher than that during either $\mathrm{A}$ or B. In ordler to evaluate this observation, a one-lway ANOVA was conducted using the individual combined rates of responding from the two test trials with each of $A, B$, and AB. This revealed a significant effect of stimulus $[F(2,58)=26.25]$. Subsequent paired comparisons confirmed that responding was significantly faster dur-

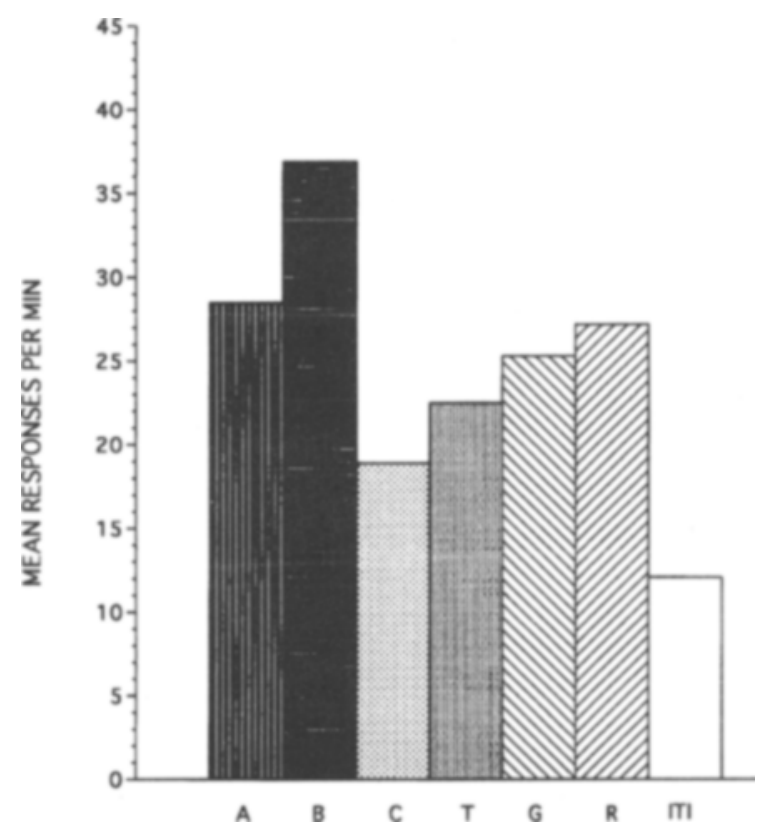

Figure 2. The combined mean rates of responding during the test trials with each of the six discriminative stimuli and during the ITI that preceded these trials in Sessions 16-22 of Experiment 2. ing $\mathrm{AB}$ than that during either $\mathrm{A}$ or $\mathrm{B}$ and responding was faster during $B$ than that during $A$.

Figure $3 \mathrm{~B}$ shows that the mean rate of responding during $\mathrm{AG}$ was higher than that during either $\mathrm{A}$ or $\mathrm{G}$. A one-way ANOVA revealed a significant effect of stimulus $[F(2,58)=15.0]$. Subsequent Newman-Keuls comparisons indicated a significantly faster rate of responding during $A G$ than during either $A$ or $G$ and a faster rate of responding during $A$ than during $G$.

Figure $3 \mathrm{C}$ shows a faster rate of responding during $\mathrm{AT}$ than during either $\mathrm{A}$ or T. A one-way ANOVA revealed a significant effect of stimulus $[F(2,58)=10.6]$. Subsequent comparisons revealed that responding was significantly faster during AT than that during either A or T and responding was faster during $A$ than that during $T$.

The results for GT, G, and T are presented in Figure 3D. Responding was faster during GT than that during either $\mathrm{G}$ or T. A one-way ANOVA indicated a significant effect of stimulus $[F(2,58)=13.7]$. Subsequent paired comparisons revealed that responding was significantly faster during GT than that during either $\mathrm{G}$ or $\mathrm{T}$, but the remaining comparison was not significant.

The results in Figure 3E indicate a marginally faster rate of responding during $\mathrm{CT}$ than during either $\mathrm{C}$ or $\mathrm{T}$. Again, a one-way ANOVA was conducted. This revealed a significant effect of stimulus $[F(2,58)=5.4]$. Subsequent tests indicated that responding was significantly faster to CT and T than it was to C, but the difference between the response rates during $\mathrm{CT}$ and $\mathrm{T}$ was not significant. Thus, the analysis indicates a failure of summation during CT.

Figure 3F indicates a marginally slower rate of responding during GR than during either $G$ or $R$. In this figure, the mean rates of responding during these three stimuli are combined for Group Adjacent and for Group Separate. The mean rates of responding per minute during GR, $G$, and $R$, respectively, were $31.4,32.5$, and 27.5 for Group Separate and 29.5, 27.9, and 26.9 for Group Adjacent. Thus, the test results suggest that performance of the two groups during the three stimuli was similar. In order to evaluate this observation, a two-way ANOVA was conducted, using the individual combined rates of responding during each of GR, G, and R for the two groups. This analysis confirmed that the performance of the two groups did not differ significantly by revealing that the effect of group and the group $\times$ stimulus interaction were not significant $(F \mathrm{~S}<1)$. The analysis also failed to reveal a significant effect of stimulus $[F(2,56)=1.26]$. These results suggest that separation of two visual stimuli in space does not enhance responding for the compound.

The results that have been presented so far revealed faster responding during AB, AG, AT, and GT than during their respective components, which suggests that, at least for these compounds, we were successful in demonstrating summation. However, a more conservative test for summation is to compare, for each subject, the rate of responding during the compound with the higher of the two rates that were recorded in the presence of the com- 

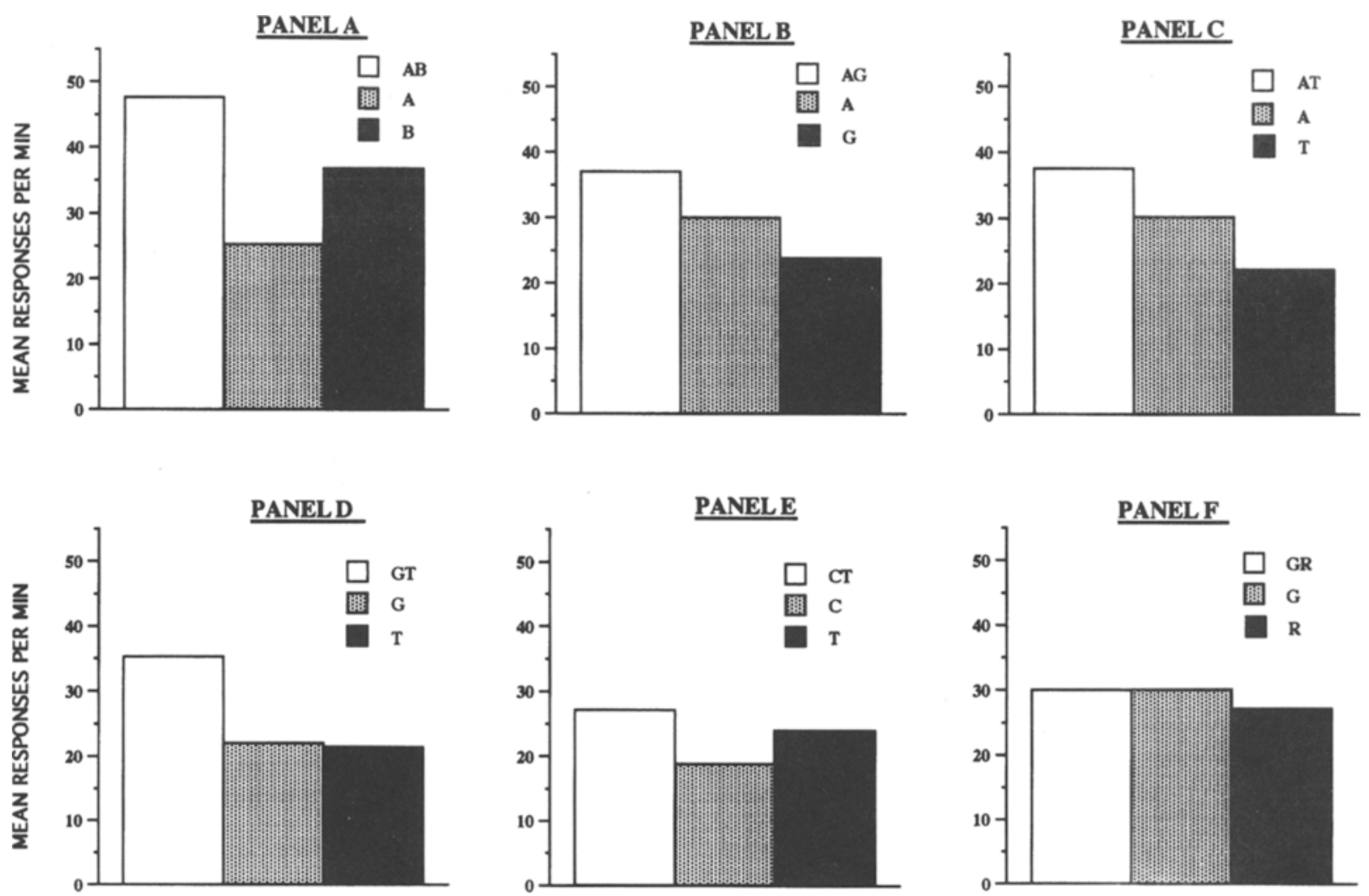

Figure 3. The mean rates of responding during the 120-sec test trials from Sessions 16-22 in Experiment 2. Each panel of the-figure displays the mean rates of responding during a test compound and its components.

ponents (Meltzer \& Hamm, 1976). The means of the higher response rates for the pairs of stimuli from $A B$, AG, GT, and AT, respectively, were $39.1,31.9,28.1$, and 33.2 responses per minute. A comparison of the individual response rates contributing to these means with those recorded during the relevant compound revealed that responding during the compound was significantly faster for $\mathrm{AB}, \mathrm{AG}$, and $\mathrm{GT}[\mathrm{ts}(29)>3.0]$, but not for $\mathrm{AT}$.

Tests with $A$ and $B$. The mean number of responses per minute during the test trials with $A$ and $B$, respectively, were 33.0 and 40.5 when the region of the television screen that was not occupied by these stimuli was white. When this region of the screen was dark, then the response rates were reduced to 22.5 and 31.0. Responding during the ITI that preceded these trials was 11.9 responses per minute. A comparison of individual mean rates of responding revealed that each of the subjects responded faster during the test trials than the ITI. A twoway ANOVA with the factors of background (white or black) and of stimulus (A and $B$ ) was conducted. This indicated a significantly faster rate of responding during $\mathrm{B}$ than during $\mathrm{A}[F(1,29)=8.6]$. In addition, responding was significantly faster to $A$ and $B$ in the presence of the white background stimulus than in the absence of the white background stimulus $[F(1,29)=5.4]$. The interaction between the two factors was not significant $(F<1)$.
Tests with $A A$ and $B B$. The mean rates of responding during the test presentations with $\mathrm{A}, \mathrm{B}, \mathrm{AA}, \mathrm{BB}$, and $\mathrm{AB}$ and during the ITI in the final two sessions of the experiment, respectively, were $31.6,32.6,23.2,31.5,40.4$, and 13.1 responses per minute. A comparison of individual mean rates of responding showed that each subject responded more rapidly during the test trials than during the ITI. Furthermore a one-way ANOVA, using individual mean rates of responding during each of the five test trials in the final two sessions, revealed a significant effect of stimulus $[F(4,116)=8.4]$. Subsequent paired comparisons indicated that responding was significantly faster during $A B$ than during the remaining stimuli and that responding was significantly slower during AA than during the remaining four stimuli. None of the other comparisons was significant.

\section{Discussion}

One conclusion that can be drawn from Experiment 2 is that summation with two visual stimuli is not more likely to occur when they are placed apart than when they are together. Thus, the failure to observe summation when the components of GR were presented side by side (Group Adjacent) was matched by a similar failure when $G$ and $R$ were located on opposite walls of the chamber (Group Separate). In addition, summation was clearly evident 
with two adjacent visual stimuli, $\mathrm{A}$ and $\mathrm{B}$, and there was no indication that the magnitude of this effect was greater during $A G$, which was composed of two visual stimuli in different locations.

As far as stimulus modality is concerned, we found summation with compounds composed of stimuli from different modalities as well as from the same modality. Thus, the results clearly demonstrate that summation does not depend upon the use of stimuli that belong to different modalities. We should note, however, that the only failures to obtain summation were with stimuli from the same modality.

Finally, the effect of combining stimuli that were presented on the television screen appears to be influenced by the illumination of the remainder of the screen. Experiment 1 revealed that when the screen that is not occupied by the experimental stimuli is dark, both during a trial and during the ITI, then summation is not observed. However, in Experiment 2, where the screen was white during the ITI and in the region not occupied by A and $\mathrm{B}$ on conditioning trials, summation was observed. One explanation for the role of the white screen is that it acquired inhibitory properties as a result of its presence during the ITI. If this is correct, then in order to counteract the inhibitory influence of the white screen during the conditioning trials with $\mathrm{A}$ and $\mathrm{B}$, these stimuli might have acquired abnormally high excitatory properties (see Wagner, 1971). Evidence of these properties should then be revealed by faster responding during either A or B when they are presented against a black background rather than a white background. In fact, test trials in which the white screen that accompanied A or B was replaced by darkness had the opposite effect of weakening responding. Moreover, the results from the final test sessions found that responding during $\mathrm{AA}$ or $\mathrm{BB}$ was much the same as during $A$ or $B$ when they were accompanied by the white screen. Such an outcome would not be expected if the presence of the white screen exerted an inhibitory influence on responding during A or B.

\section{EXPERIMENT 3}

The implication of the first two experiments is that when stimuli are presented on a television screen for operant conditioning, then the color of the remainder of the screen is an important determinant of whether or not summation will be observed. When the area that is not occupied by the experimental stimuli, both during the trial and during the ITI, is black, then the results of Experiment 1 suggest that summation will not occur. But when this part of the screen is white, then the results of Experiment 2 indicate that summation will be observed. The purpose of Experiment 3 was to confirm these observations in a single experiment with one group of pigeons.

Subjects were trained to peck a response key in the presence of each of four colored triangles (A, B, C, and D). Whenever A or B was presented, the remainder of the screen was white. In addition, the entire screen was also illuminated white during the ITI prior to the presentation of these stimuli. When either C or D was presented, the remainder of the screen was dark. The entire screen during the ITI that preceded the presentations of C and D was also dark. Following conditioning, the pigeons received test trials with $\mathrm{AB}$ and $\mathrm{CD}$, as well as their components. The findings of Experiments 1 and 2 suggest summation should be observed with $A B$, but not with $C D$.

\section{Method}

Subjects. The subjects were 16 adult homing pigeons from the same stock and housed in the same manner as those in Experiment 1 . They had participated in an autoshaping experiment in which stimuli were colored small rectangles similar to those used by Pearce and Redhead (1993). The apparatus was the same as that used in Experiment 1.

Stimuli. For half of the subjects, A and B were the triangles used for Experiment 2. Triangle $\mathrm{C}$ was composed of alternating red and cyan squares, the sides of which were equal to one tenth of the height of the screen. Triangle $D$ was green. For the remainder of the subjects, $A, B, C$, and $D$, respectively, were the same as $C, D, A$, and $B$ for the subjects just considered. Triangles $A$ and $C$ were always presented in the upper half of the screen, whereas B and D were always presented in the lower half. Moreover, when either A or B, but not $C$ or $D$, was presented individually, the remaining half of the screen was illuminated white. A white line with a width of $0.4 \mathrm{~cm}$ separated A and B when they were presented together, whereas a black line of the same width separated $C$ and $D$ when they were presented together.

Procedure. In every session of the experiment, there were six presentations for 2 min of A, B, C, and D in a random order, with the constraint that no less than two and no more than four trials with either A or B, or C or D, occurred in succession. An interval of 2 min separated successive trials, during which the entire television screen was illuminated white if the forthcoming trial was with A or $\mathrm{B}$; otherwise, the screen was dark. For Sessions 1-8, four VI 60-sec reinforcement schedules were separately in effect during $\mathrm{A}, \mathrm{B}, \mathrm{C}$, and D. For Sessions 9-24, the schedules of reinforcement were VI $120 \mathrm{sec}$. For the remaining 9 sessions of the experiment, they were VI $180 \mathrm{sec}$.

In each of the final two sessions of the experiment (Sessions 33 and 34), there were two test trials with $\mathrm{AB}$ and $\mathrm{CD}$. The television screen was illuminated white prior to the trials with $\mathrm{AB}$, but not with $\mathrm{CD}$. One randomly selected training trial with each of $\mathrm{A}, \mathrm{B}, \mathrm{C}$, and $D$ was treated as a test trial. Food was not presented in any test trial. The sequence of the test trials was altered randomly for different subgroups of 4 subjects. There were at least two training trials between successive test trials. Procedural details that have been omitted were the same as those for Experiment 2.

\section{Results}

From the initial sessions onward, responding was more rapid in the presence than in the absence of $\mathrm{A}, \mathrm{B}$, $C$, and $\mathrm{D}$. In addition, the mean rate of responding during the ITI was more rapid when the screen was illuminated white than when it was black. The combined mean number of responses per minute from the test trials of the final two sessions during $\mathrm{A}, \mathrm{B}, \mathrm{AB}, \mathrm{C}, \mathrm{D}$, and $\mathrm{CD}$ were $36.8,39.8,52.4,38.7,38.3$, and 32.1 , respectively. The mean number of responses per minute during the ITI was 3.7 when the screen was white and 0.1 when the screen was black. This difference was significant $[t(15)=2.2]$. 
A comparison of individual mean rates of responding revealed that each of the subjects responded faster during the test trials with $A, B$, and $A B$ than during the ITI that preceded these trials. A similar comparison also revealed that each of the subjects responded more rapidly during the test trials with $\mathrm{C}, \mathrm{D}$, and $\mathrm{CD}$ than during the ITI preceding these test trials.

The results from the test trials suggest that responding was more rapid during $\mathrm{AB}$ than during either $\mathrm{A}$ or $\mathrm{B}$ and that responding was slower during $C D$ than during either C or D. A two-way ANOVA supported this observation, using individual mean rates of responding during each of A, B, AB, C, D, and CD, with the factors of background (black or white) and stimulus. This revealed nonsignificant effects of background $[F(1,15)=4.1]$ and stimulus $(F<1)$, but the background $\times$ stimulus interaction was significant $[F(2,30)=7.6]$. Tests for simple main effects revealed that there was a significant difference among the rates of responding during $\mathrm{A}, \mathrm{B}$, and $\mathrm{AB}[F(2,60)=5.8]$ but not during $\mathrm{C}, \mathrm{D}$, and $\mathrm{CD}$ $[F(2,60)=1.2]$. Subsequent Newman-Keuls comparisons revealed that the subjects responded significantly faster during $\mathrm{AB}$ than during either $\mathrm{A}$ or $\mathrm{B}$, but there was no difference between the rates of responding during $A$ and $B$. Further tests of simple main effects revealed that responding was significantly faster during $\mathrm{AB}$ than during $C D[F(1,45)=17.7]$, but there were no significant differences among the rates of responding during $\mathrm{A}, \mathrm{B}$, $\mathrm{C}$, and $\mathrm{D}(F \mathrm{~s}<1)$.

A comparison of the individual rates of responding during $A B$, with the higher of the two rates recorded during either $A$ or $B$, revealed that responding was significantly faster during $\mathrm{AB}[t(15)=3.1]$. The mean of the higher rates of responding during the single stimuli was 43.2 responses per minute.

\section{Discussion}

The results of Experiment 3 confirm the importance of the illumination of the response key for summation. Summation was observed during $\mathrm{AB}$, after conditioning with $A$ and $B$ in which the part of the television screen that was not occupied by these stimuli was white both before and during their presentation. Conversely, summation was not observed during $\mathrm{CD}$, after conditioning with $\mathrm{C}$ and $\mathrm{D}$ had been conducted against a context of a dark television screen.

The results from Experiment 3 are particularly intriguing when they are considered in relation to the results of studies that have failed to show summation using autoshaping with pigeons (Aydin \& Pearce, 1994, 1995; Rescorla \& Coldwell, 1995). In these experiments, the stimuli were presented on a television screen that was always dark except for the region that was occupied by the experimental stimuli. The implication of the results that have just been described is that if the television screen had been white instead of dark, then summation would have been found in those experiments. The purpose of Experiment 4 was to test this possibility.

\section{EXPERIMENT 4}

Two groups of pigeons received autoshaping for which presentations of A and B were paired with food. The stimuli were colored triangles similar to those used in Experiment 1. For Group White, whenever a stimulus was presented, the remainder of the screen was white. In addition, the entire screen was also illuminated white during the ITI. For Group Black, the screen was never illuminated white. If the presence of a white background should promote summation, then responding during test trials with $A B$ will be more rapid in Group White than in Group Black. In order to prevent any differences between the groups being masked by a performance ceiling, these test trials were conducted in extinction.

A further, within-group test for the influence of the white background was made possible by the inclusion of conditioning trials with a compound $\mathrm{CD}$ during the first stage of the experiment. This compound was presented to both groups in extinction intermixed with the extinction trials with $\mathrm{AB}$. The associative strength of $\mathrm{CD}$ can reasonably be expected to be at asymptote at the outset of the test trials. If the presence of the white background should promote a summation of the associative properties of $A$ and $B$ when they are presented together, then responding during the test trials with $\mathrm{AB}$ will be more vigorous than that during $C D$ in Group White. On the other hand, the results from previous autoshaping experiments suggest that such a summation effect will not be evident in Group Black, for which responding during $\mathrm{AB}$ will be similar to that during CD.

This indirect method of testing for summation was adopted because of a concern that the area occupied by the stimulus on the television screen might influence the rate of responding in its presence. Rescorla and Coldwell (1995) reported that the rate of autoshaped keypecking tends to be inversely related to the area of the stimulus to which it is directed. The occurrence of such an effect in Experiment 4 might obscure any evidence of summation, if the rate of responding during $\mathrm{AB}$ was compared with that during its components.

There was one further concern that influenced the design of Experiment 4 . If subjects simply received conditioning with $\mathrm{A}, \mathrm{B}$, and $\mathrm{CD}$, then keypecking might conceivably be controlled by some general characteristic of these stimuli-such as a change in illumination-rather than by their specific properties. If this were the case, then presenting $A B$ might not have any special effect in either group. In order to ensure that subjects attended to the specific features of the stimuli with which they were trained, additional nonreinforced trials were presented with $\mathrm{E}, \mathrm{F}$, and $\mathrm{EF}$.

\section{Method}

Subjects. The subjects were 36 naive adult homing pigeons from the same stock and housed in the same manner as those in Experiment 3. The apparatus was also the same as that used in Experiment 3 . The subjects were randomly allocated to two groups of equal number at the start of the experiment. 
Stimuli. Stimuli A, B, C, and D were the triangles used in Experiment 3. For each group, they were counterbalanced in the manner described for Experiment 3. For all subjects, Triangles $E$ and $F$ were composed of alternating cyan and yellow vertical stripes, each of which was $0.5 \mathrm{~cm}$ wide. Triangle $E$ was always presented in the upper half of the screen, whereas $F$ was always presented in the lower half. Whenever a single triangle was presented by itself, the remaining half of the screen was white for Group White. For this group, the screen was also illuminated white during the ITI. For the subjects in Group Black, the screen was never illuminated white. The remaining details concerning the stimuli were the same as those for Experiment 3.

Procedure. All subjects first received three sessions of magazine training. For the next 13 sessions of autoshaping, A, B, and CD were followed by food for $4 \mathrm{sec}$, but presentations of $\mathrm{E}, \mathrm{F}$, and $\mathrm{EF}$ were never followed by food. There were eight presentations with each of the six stimuli in every session, and the stimulus duration was $10 \mathrm{sec}$. The trials were presented in a random sequence, with the constraint that no more than two trials of the same type could occur in succession.

For the first 24 trials of Session 14, autoshaping continued in the same manner as for Session 13. For the next 24 trials, $\mathrm{AB}$ and $\mathrm{CD}$ were presented in an alternating sequence in extinction. For half of the subjects in each group, this sequence commenced with AB; for the remaining subjects, it commenced with $\mathrm{CD}$. The ITI was $55 \mathrm{sec}$ during every session of the experiment.

\section{Results}

One subject in Group Black failed to peck, and its data were not included in any of the analyses. The mean responses per minute for the reinforced trials, for the nonreinforced trials (CSO), and for the ITI during each of the 14 sessions are presented in the left-hand panel of Figure 4 for Group White and in the right-hand panel of Figure 4 for Group Black. From the initial sessions onward, both groups responded faster on the reinforced trials than on the nonreinforced trials. Responding during the ITI was slow. A comparison of the individual mean rates of responding from the first half of Session 14 revealed that every subject in each group responded more rapidly during each type of reinforced trial than during the nonreinforced trials. Moreover, a two-way ANOVA, using individual mean rates of responding during each of $A, B$, and CD for the two groups in the first half of Session 14 failed to reveal any significant effects of group, stimulus, and group $\times$ stimulus interaction $\left(F_{\mathrm{s}}<1\right)$. A two-way ANOVA was conducted in order to compare the performance of the two groups during the ITI in each of the 14 sessions. This revealed a nonsignificant effect of group $[F(1,33)=1.5]$, but the effect of session and the group $\times$ session interaction were both significant $[F \mathrm{~s}(13,429)>5.0]$. Subsequent tests for simple group effects revealed that responding was significantly faster by Group White than by Group Black in Sessions 2 and 3 and that responding was significantly slower by Group White than by Group Black in Session $1[F \mathrm{~s}(1,462)>4.2]$.

The mean rates of responding by the two groups during $A B$ and $C D$ in the second half of Session 14 are presented in Figure 5. Group White, in general, responded faster during $A B$ than during $C D$, whereas the opposite outcome was observed for Group Black. A three-way ANOVA with the factors of group, stimulus, and trial was conducted. The most important outcome of the analysis was a significant three-way interaction $[F(11,363)=$ 2.5]. To explore the interaction further, tests for simple interaction effects were conducted for the individual trials. These revealed significant group $\times$ stimulus inter-
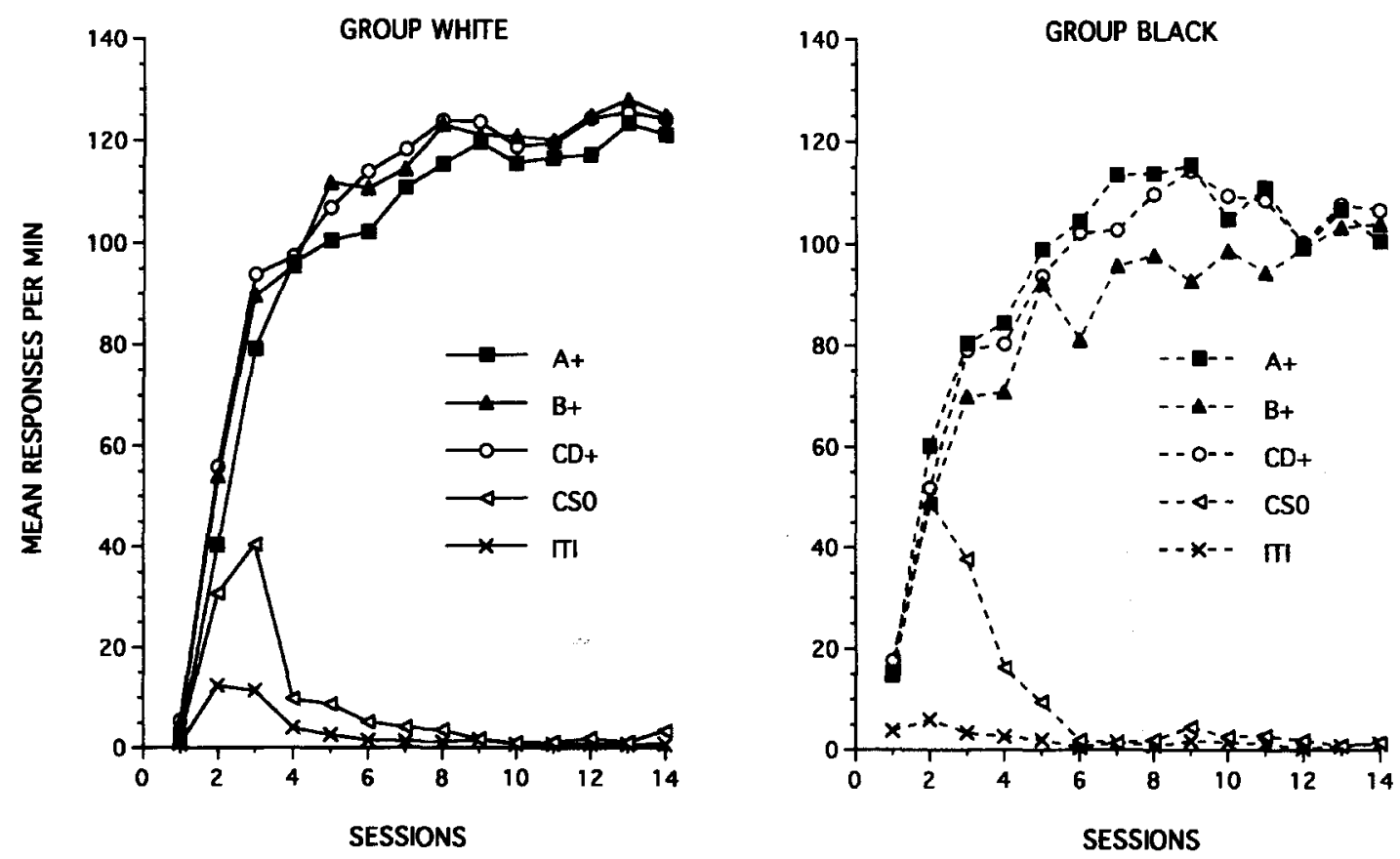

Figure 4. The mean rates of responding during different types of training trials and during ITI in each session of Experiment 4 for Group White and for Group Black. 


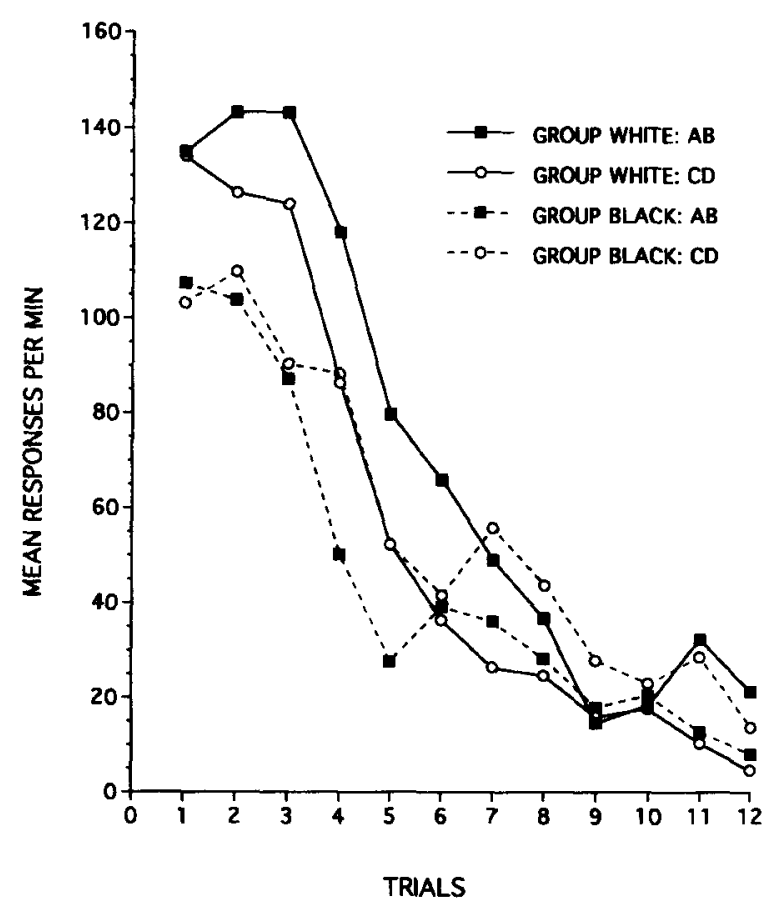

Figure 5. The mean rates of responding during the test trials with Compounds $A B$ and $C D$ for Group White and for Group Black in Experiment 4.

actions for Trials $4,5,6,7$, and $11[F \mathrm{~s}(1,396)>5.8]$. Further tests for simple stimulus effects revealed that, during each of these trials, Group White responded significantly faster during $\mathrm{AB}$ than during $\mathrm{CD}[F \mathrm{~s}(1,396)>3.9]$, whereas Group Black responded significantly slower during $\mathrm{AB}$ than during $\mathrm{CD}$ on Trials 4 and $5\left[F_{\mathrm{s}}(1,396)>4.9\right]$. In addition, a test for simple group effects showed that the rate of responding was significantly higher during $\mathrm{AB}$ for Group White from Trial 2 to Trial 5 than for Group Black $[F \mathbf{s}(1,792)>5.1]$. The equivalent test using the rates of responding during $C D$ failed to reveal a significant group difference on any of the trials $\left[F_{\mathrm{s}}(1,792)<3.7\right]$.

The remaining outcomes of the three-way ANOVA were as follows. There were significant effects of trial $[F(11,363)=44.4]$ but not of stimulus and group $[F \mathrm{~s}(1,33)<1.6]$. The group $\times$ stimulus $[F(1,33)=9.0]$ and the group $\times$ trial interactions $[F(11,363)=2.3]$ were both significant, but the stimulus $\times$ trial interaction was not significant $(F<1)$.

\section{Discussion}

In Experiment 4, autoshaping was conducted with individual stimuli (A and $B$ ) that were presented on a television screen. The effect of combining these stimuli was greatly influenced by the manner in which the television screen was illuminated in the absence of these stimuli. When the screen was illuminated white in the region that was not occupied by the stimuli, and during the ITI, responding during $\mathrm{AB}$ was faster than it was for a group that received identical training except that the screen was dark rather than white.

A further finding of the experiment is that the presence of the white screen resulted in significantly faster responding during $\mathrm{AB}$ than during a control compound, $\mathrm{CD}$. This finding does not constitute a conventional demonstration of summation, in which the rate of responding during $\mathrm{AB}$ would be compared with that during its components. Nonetheless, the results for Group White demonstrate for the first time with autoshaping that separate conditioning with two stimuli can result in an abnormally high rate of responding when they are presented together.

\section{GENERAL DISCUSSION}

In four experiments, some of the factors that determine whether or not summation will be observed with pigeons were examined. Presenting together two stimuli that had separately signaled food resulted in an abnormally high rate of responding. This effect was found with both operant and Pavlovian conditioning. It was also found with stimuli from the same modality and with stimuli from different modalities. But perhaps the most original finding of the experiments is that the level of illumination behind the response key is an important determinant of summation. Summation was found when the level of this illumination was high, but not when it was low, throughout the experimental session.

When a compound of two stimuli is presented to a subject, then the simplest assumption is that responding will be governed by whichever stimulus possesses the greater associative strength. This assumption explains our failures to observe summation in each of the four experiments, but some additional, nonassociative process must then be invoked in order to explain our successful demonstrations of summation.

One process could have its basis in the possibility that the intensity of a stimulus, or a compound, influences the strength of responding in its presence (e.g., Hull, 1943). In a summation experiment, the intensity of stimulation of the test compound trial will be greater than that of each training stimulus, and this factor alone might be responsible for any summation effect that is observed. Support for this proposal can be found in experiments where responding during a conditioned stimulus is enhanced by presenting it together with an associatively neutral stimulus (e.g., Aydin \& Pearce, 1995; Carter, Salive, \& Zajonc, 1966; Pavlov, 1927, pp. 93, 95). The summation effects described in Experiment 2 could have been a consequence of this influence of stimulus intensity, but it is unlikely to have been responsible for the high rate of responding during the tests with $\mathrm{AB}$ in Experiment 4 for Group White. Responding during $\mathrm{AB}$ was faster than that during a control compound, $C D$, which was of equal intensity to $A B$ but for which the components had not been individually paired with food. By appealing solely to the influence of 
stimulus intensity, it is also difficult to explain the faster responding during $\mathrm{AB}$ than during $\mathrm{CD}$ in Experiment 3.

Another nonassociative explanation for summation has been evaluated by Aydin and Pearce (1995). Using autoshaping, we tested for summation with stimuli of sufficient duration to ensure that responding was slower at their beginning than at their end. This effect was attributed to inhibition of delay (see also Kimmel \& Greene, 1964; Pavlov, 1927; Prokasy, 1965; Smith, 1968). When the stimuli were presented in compound, then an enhancement of responding was observed, but only for the initial few seconds of each trial, which suggests that one stimulus served to disinhibit the weak responding elicited by the other. In support of this latter proposal, we found an equal enhancement of responding at the onset of a test compound when it was composed of either two excitatory stimuli or an excitatory and a neutral stimulus.

Again, this type of effect is unlikely to have been responsible for all of our results. In Experiment 3, for example, any disinhibitory effect of presenting A and B together should also have occurred when testing was conducted with $C$ and $D$; yet it was only with the former pair of stimuli that a summation effect was observed. Likewise, in Experiment 4, any effect of disinhibition would be expected to enhance responding during the compound test trials in both groups. But it was only with Group White that summation was observed.

The summation effects that we have reported are thus difficult to explain if it is assumed that the associative properties of only a single stimulus determine responding during a compound. Instead, the results show that responding is determined by some sort of interaction between the associative properties of both stimuli (see also Meltzer \& Niebuhr, 1974; Weiss, 1976). A common suggestion concerning the nature of this interaction is that, when two or more stimuli are presented in compound, responding is determined by the sum of their associative properties (Hara \& Warren, 1961; Hull, 1943; Konorski, 1948; McGonigle, 1967; Pavlov, 1927; Pearce \& Hall, 1980; Rescorla \& Wagner, 1972; Spence, 1936; Weiss, 1972). This proposal is able to explain our successful demonstrations of summation. We consider below a variety of ways in which it might be elaborated in order to explain our failures to detect summation.

Pavlov (1927) reported that presenting a novel stimulus with a conditioned stimulus can, under certain conditions, temporarily weaken responding through a process that he referred to as external inhibition. Thus, in Experiment 1 , presenting two stimuli together for the test trials might have resulted in external inhibition, which countered any tendency for associative summation. Unfortunately, until more is known about the factors that promote external inhibition, its role in the present experiments will be difficult to ascertain. For example, Experiment 2 revealed summation with $A B$ but not with $G R$, which suggests that presenting $\mathrm{G}$ and $\mathrm{R}$ together promoted greater external inhibition than did combining $\mathrm{A}$ and $\mathrm{B}$. Why this should be the case is not at all clear.
According to Hull (1943), the way in which a stimulus is perceived can be altered when it is accompanied by another stimulus. As a consequence, if two stimuli are presented together, after they have been presented for conditioning separately, their associative properties will suffer a generalization decrement. If this decrement is sufficiently large, then, even though the properties of the two stimuli combine together, responding during the compound may be no greater than that during either element alone. In a similar manner, Rescorla and Coldwell (1995) have proposed that when two visual stimuli are presented together, after having separately signaled food for autoshaping, their integrity will be lost by virtue of a perceptual interaction. As a consequence, the contribution made by each stimulus to responding during the compound will be less than would be the case if they are presented alone.

Thus, our failures to obtain summation might have occurred because the manner of testing might have reduced the effectiveness of the training stimuli. On the other hand, our successful demonstrations of summation can be attributed to the use of stimuli that interact only slightly at a perceptual level. A problem with these proposals is that they are hard to evaluate because so little is known about the way in which the perception of one stimulus can be influenced by the presence of another. In Experiment 2, for example, summation was not observed when the red and green light panels on opposite walls of the chamber were illuminated simultaneously; whereas the illumination of the green light panel together with the presentation of a stimulus on the television screen did result in summation. These contrasting results can be explained by appeal to a perceptual interaction, but it is difficult to see how this explanation can be justified.

Another possibility is that presenting stimuli together results in associative summation, but this effect is influenced by stimulus generalization. From the perspective of Rescorla and Wagner's (1972) model, generalization between two stimuli is possible if they share a common element (Blough, 1975; Rescorla, 1976). Thus, two stimuli (A and B) can be conceptualized as $a x$ and $b x$, where $a$ and $b$ refer to the distinctive features of the two stimuli and $x$ is their common feature. If we now assume that presenting the two stimuli together creates the compound $a b x$, then, after conditioning with each stimulus alone, the strength of responding during the compound will be determined by the salience of $x$. If $x$ is much more salient than $a$ or $b$, then it will acquire most of the associative strength during conditioning, and the compound will elicit a similar response to its components. But if the salience of $x$ is low, then $a$ and $b$ will acquire most of the associative strength during conditioning, and summation should be observed with the compound. A tone and clicker are likely to share an element of greater salience than that shared by a tone and a green panel of light. Accordingly, this type of analysis correctly predicts for Experiment 2 that summation will be more evident with a compound of the tone and green panel of light than with the tone and clicker (see also Kehoe et al., 1994). 
In a rather similar way, Rescorla and Wagner's (1972) model can also explain the influence of the white background on summation in Experiments 2, 3, and 4. Suppose that $\mathrm{A}$ and $\mathrm{B}$ share a common feature, $x$, with the white background that contains the unique feature $w$. Conditioning with $\mathrm{A}$ and $\mathrm{B}$ against this background can then be construed as reinforced trials with $a w x$ and $b w x$, together with nonreinforced exposure to $w x$ during the ITI. Assuming that $w$ and $x$ are of approximately equal salience, Rescorla and Wagner's (1972) model predicts that they will ultimately have negligible associative strength, whereas $a$ and $b$ will attain an asymptotic level of associative strength. Presenting $A$ and $B$ together will then permit the associative properties of $a$ and $b$ to combine, and a summation effect should be observed.

A problem for this type of explanation is raised by the failure to observe summation in Experiment 1, which included nonreinforced $(-)$ trials with Triangles $C$ and $D$ in addition to the reinforced $(+)$ trials with $A$ and $B$. Conditioning in this experiment can be characterized as $a x+$, $b x+, c x-$, and $d x-$ (where $a, b, c$, and $d$ represent the unique features of $\mathrm{A}, \mathrm{B}, \mathrm{C}$, and $\mathrm{D}$, and $x$ is a feature shared by all four stimuli). In these circumstances, the presence of the common feature is predicted to have only a relatively small influence on summation. (Note that this prediction holds no matter what value is assigned to the salience of $x$, relative to $a, b, c$, and $d$.) The failure to observe summation in Experiment 1 is thus difficult to explain if it is assumed that responding during a compound is determined by the sum of the associative properties of its components, even if stimulus generalization is taken into account.

The final explanation to be considered for our results is derived from configural theories of conditioning (e.g., Pearce, 1987, 1994). According to this type of account, when a stimulus or compound is repeatedly paired with a reinforcer, a single association will develop between representations of the two events. If two stimuli should be presented together after they have separately been used for conditioning, then configural theory predicts that the strength of responding during the compound will be determined by the amount of excitation that generalizes to it from the elements. If the elements are of equal salience, Pearce (1987) has argued that half of their associative strengths will generalize to the compound, and it should elicit a similar level of responding as that seen during the individual stimuli. Thus, configural theory can explain the failures to obtain summation that we described in each experiment, but it is unable to account for the occasions on which this effect was demonstrated.

To overcome this deficiency, the theory could acknowledge that the contextual stimulation that accompanies conditioning may enter into configural associations. Thus, as a result of pairing $A$ and $B$ with food in context $C$, configurations of $\mathrm{AC}$ and $\mathrm{BC}$ will enter into excitatory associations. The effects of these associations will then generalize to those periods when $C$ is present by itself and will result in responding during the ITI. To counter this influence, inhibition to the context will develop that, in turn, will generalize to $\mathrm{AC}$ and $\mathrm{BC}$ and weaken responding in their presence. The compounds will then have to acquire an unusually high level of excitatory strength in order to elicit a normal rate of responding. Finally, the test compound will create a new configuration, $\mathrm{ABC}$, that will receive a substantial generalization of excitatory strength from $\mathrm{AC}$ and $\mathrm{BC}$. The combined effects of this generalization will then permit an abnormally high level of responding during the test compound. A detailed presentation of this analysis, of what is effectively an $\mathrm{AC}+\mathrm{BC}+$ $\mathrm{C}$ - discrimination, is provided by Pearce, Adam, Wilson, and Darby (1992), who show, by means of a computer simulation, that the predicted excitatory strength of the test compound $A B C$ is $1.33 \lambda$, where $\lambda$ is the asymptote for conditioning. In fact, this prediction is made only if the salience of $C$ is assumed to be the same as that of $A$ and $B$. As the salience of $C$ is reduced below this value, so the predicted strength of responding during $\mathrm{ABC}$ declines. In the limiting case, where the salience of $\mathrm{C}$ is negligible, then (as shown above) responding during the compound will be the same as that during A or B. Thus, configural theory predicts summation will be possible if conditioning allows contextual stimuli to be prominent in any excitatory configural representations that develop.

Consider now the training that was given with the tone $(\mathrm{T})$ and the green panel of light $(\mathrm{G})$ in Experiment 2. To gain reward, pigeons were expected to peck a key in front of a white television screen whenever these stimuli were presented, but pecking in front of the white screen in the absence of these stimuli was never rewarded. It is thus plausible that the white screen entered into excitatory configural associations on trials with $T$ and $G$ and into an inhibitory association during the ITI. As a result, the training can be characterized as $\mathrm{TW}+\mathrm{GW}+\mathrm{W}-$. Since the test trials were also conducted when the television screen was white, they can be characterized as TGW, and, on the basis of the discussion above, configural theory correctly predicts that summation should be observed.

In Experiment 2, there were also test trials with a clicker-tone compound and with a compound composed of the red and green panels of light. Since training and testing with these stimuli were conducted with the television screen illuminated white, then presenting the compounds should have resulted in summation. But there was no hint of this effect on the test trials. These results can be explained, however, if it is assumed that there is generalization between stimuli that belong to the same modality. Such an effect will restrict the amount of excitation that is associated with each configuration that is paired with food, which, in turn, will restrict the amount of generalization to the test compound.

The analysis that has just been developed is not appropriate for stimuli presented on the television screen when it was white. The training with these stimuli can be characterized as $\mathrm{AW}+\mathrm{BW}+\mathrm{W}-$, and the test trials when $A$ and $B$ were presented together can be characterized as AB. According to Pearce $(1987,1994)$ only a quarter of the associative strength of $\mathrm{AW}$ will generalize to $\mathrm{AB}$ in these circumstances, which will be insufficient to promote 
summation; however, in Experiments 2, 3, and 4, this effect was found. These results can be explained by assuming that there was generalization between the training stimuli and the white background. To help present this explanation clearly, the training can be characterized as $a x w+b x w+w x-$, and the test compound can then be represented as $a b x$. Since the amount of generalization between two configurations is determined by the proportion of elements that they share, there will be a considerable generalization of excitation to $a b x$ and rather little generalization of inhibition. Using equations specified in Pearce (1987), and assuming that the salience of the elements is equal, a more formal derivation of a prediction concerning the test trial revealed that the associative strength generalizing to $a b x$ will be $1.2 \lambda$.

At an empirical level, our results may be of interest for two reasons: (1) They confirm that a summation effect can be obtained using autoshaping with pigeons. (2) They show also that when conditioning is conducted with visual stimuli, then summation is influenced by the way in which the response key is illuminated during and prior to these stimuli. There are a variety of ways in which our results can be explained. A choice between them, however, must be deferred until further experiments have evaluated critically the various assumptions that were made in developing these explanations.

\section{REFERENCES}

Aydin, A., \& Pearce, J. M. (1994). Prototype effects in categorization by pigeons. Journal of Experimental Psychology, 20, 264-277.

Aydin, A., \& Pearce, J. M. (1995). Summation in autoshaping with short and long-duration stimuli. Quarterly Journal of Experimental Psychology, 48B, 215-234.

BLough, D. S. (1975). Steady state data and a quantitative model of operant generalization and discrimination. Journal of Experimental Psychology: Animal Behavior Processes, 1, 3-21.

Carter, D. E., Salive, H. T., \& Zajonc, R. B. (1966). Sensory interaction: Control of auditory discrimination by visual stimulation in the pigeon. Perception \& Psychophysics, 1, 242-244.

Emurian, H. H., \& Weiss, S. J. (1972). Compounding discriminative stimuli controlling free-operant avoidance schedules. Journal of the Experimental Analysis of Behavior, 17, 249-256.

Fleshler, M., \& HoffMAN, H. S. (1962). A progression for generating variable-interval schedules. Journal of the Experimental Analysis of Behavior, 5, 529-530.

HАмм, R. J. (1977). A test for response summation with key-projected stimuli. Bulletin of the Psychonomic Society, 9, 40-42.

HAMM, R. J., \& MELTZER, D. (1973). A test for both positive and negative response summation in the pigeon. Bulletin of the Psychonomic Society, 2, 433-435.

HAMm, R. J., PorTER, J. H., \& OSTER, G. D. (1978). Compound stimulus control of operant, but not adjunctive, behavior. Bulletin of the Psychonomic Society, 12, 167-170.

HARA, K., \& WARREN, J. M. (1961). Stimulus additivity and dominance in discrimination performance by cats. Journal of Comparative \& Physiological Psychology, 54, 86-90.

HENDRY, J. S. (1982). Summation of undetected excitation following extinction of the CER. Animal Learning \& Behavior, 10, 476-482.

Hulı, C. L. (1943). Principles of behavior. New York: Appleton-CenturyCrofts.

KEHOE, E. J. (1986). Summation and configuration in conditioning of the rabbit's nictitating membrane response to compound stimuli. Journal of Experimental Psychology: Animal Behavior Processes, 12, 186-195.
Kehoe, E. J., Horne, A. J., Horne, P. S., \& Macrae, M. (1994). Summation and configuration between and within sensory modalities in classical conditioning of the rabbit. Animal Learning \& Behavior, 22, 19-26.

Kimmel, H. D., \& Greene, W. A. (1964). Disinhibition in GSR conditioning as a function of the number of CS-US trials and temporal location of the novel stimulus. Journal of Experimental Psychology, 68, 567-572.

KONORSKI, J. (1948). Conditioned reflexes and neuron organization. Cambridge: Cambridge University Press.

LoLorDo, V. M., \& HART, C. L. (1972). The effects of compounding discriminative stimuli that control variable-interval limited-hold avoidance. Psychonomic Science, 29, 147-148.

LONG, C. K., \& ALLEN, J. D. (1974). Stimulus compounding in pigeons. Bulletin of the Psychonomic Society, 4, 95-97.

MCGoNigle, B. (1967). Stimulus additivity and dominance in visual discrimination performance by rats. Journal of Comparative \& Physiological Psychology, 64, 110-113.

Meltzer, D., \& Hamm, R. J. (1976). Response summation in the pigeon. Bulletin of the Psychonomic Society, 7, 515-518.

Meltzer, D., \& Niebuhr, B. R. (1974). Additive and suppressive response summation with a chain schedule. Journal of the Experimental Analysis of Behavior, 22, 519-524.

MilleR, L. (1971). Compounding of discriminative stimuli from the same and different sensory modalities. Journal of the Experimental Analysis of Behavior, 16, 337-342.

MiLleR, L. (1974). Compounding of discriminative stimuli from the same and different sensory modalities which maintain responding on separate levers. Bulletin of the Psychonomic Society, 4, 426-428.

MiLilier, P. J., \& BEALE, I. L. (1977). Response summation to a compound stimulus in a context of choice. Journal of the Experimental Analysis of Behavior, 25, 17-21.

Pavlov, I. P. (1927). Conditioned reflexes (G. V. Anrep, Trans.). London: Oxford University Press.

Pearce, J. M. (1987). A model of stimulus generalization for Pavlovian conditioning. Psychological Review, 94, 61-73.

PeARCE, J. M. (1994). Similarity and discrimination: A selective review and a connectionist model. Psychological Review, 101, 587-607.

Pearce, J. M., AdaM, J., Wilson, P. N., \& Darby, R. J. (1992). Effects of discrimination training on responding during a compound conditioned stimulus. Journal of Experimental Psychology: Animal Behavior Processes, 18, 379-386.

Pearce, J. M., \& Hall, G. (1980). A model for Pavlovian learning: Variations in the effectiveness of conditioned but not of unconditioned stimuli. Psychological Review, 87, 532-552.

PearCe, J. M., \& Redhead, E. S. (1993). The influence of an irrelevant stimulus on two discriminations. Journal of Experimental Psychology: Animal Behavior Processes, 19, 180-190.

Prokasy, W. F. (1965). Classical eyelid conditioning: Experimenter operations, task demands, and response shaping. In W. F. Prokasy (Ed.), Classical conditioning: A symposium (pp. 208-225). New York: Appleton-Century-Crofts.

Rescorla, R. A. (1976). Stimulus generalization: Some predictions from a model of Pavlovian conditioning. Joumal of Experimental Psychology: Animal Behavior Processes, 2, 88-96.

ResCorla, R. A., \& COLDWEll, S. E. (1995). Summation in autoshaping. Animal Learning \& Behavior, 23, 314-326.

RESCORLA, R. A., \& WAGNER, A. R. (1972). A theory of Pavlovian conditioning: Variations in the effectiveness of reinforcement and nonreinforcement. In A. H. Black \& W. F. Prokasy (Eds.), Classical conditioning II: Current research and theory (pp. 64-99). New York: Appleton-Century-Crofts.

Sмrтн, M. C. (1968). CS-US interval and US intensity in classical conditioning of the rabbit's nictitating membrane response. Journal of Comparative \& Physiological Psychology, 66, 679-687.

SPENCE, K. W. (1936). The nature of discrimination learning in animals. Psychological Review, 43, 427-449.

STRUB, H., \& BARSKE, B. W. (1977). A stimulus-compounding assay of conditioned inhibition and excitation. Learning \& Motivation, 8 , 414-428.

VAN HOUTEN, R., \& RUdOLPH, R. (1971). Summation of punishment 
suppression. Journal of the Experimental Analysis of Behavior, 15, 117-121.

WAGNER, A. R. (1971). Elementary associations. In H. H. Kendler \& J. T. Spence (Eds.), Essays in neobehaviorism: A memorial volume to Kenneth W. Spence (pp. 187-213). New York: Appleton-CenturyCrofts.

WEISs, S. J. (1972). Stimulus compounding in free-operant and classical conditioning: A review and analysis. Psychological Bulletin, 78, 189-208.

WEISS, S. J. (1976). Stimulus control of free-operant avoidance: The contribution of response rate and incentive relations between multipleschedule components. Learning \& Motivation, 7, 477-516.

WeIss, S. J. (1977). The isolation of stimulus-reinforcer associations es- tablished with multiple schedules. Animal Learning \& Behavior, 5, 421-429.

WhITLOW, J. W., \& WAGNER, A. R. (1972). Negative patterning in classical conditioning: Summation of response tendencies to isolable and configural components. Psychonomic Science, 27, 299-301.

Wiltz, R. A., JR., Boren, J. J., Moerschbaecher, J. M., Creed, T. L., \& SCHROT, J. F. (1973). Generalization gradients and combinedstimulus control after equal training with two related stimuli. Psychological Reports, 32, 1003-1008.

(Manuscript received December 6, 1995; revision accepted for publication April 19, 1996.) 